\title{
Prediction and Simulation for Turning Chatter Control by Spindle Speed Variation
}

\author{
Huei-Min Lin*, J.-J. Junz Wang, Kuo-Shen Chen \\ a Department of Mechanical Engineering, National Cheng-Kung University, No.1, University Road, Tainan City 701, \\ Taiwan (R.O.C) \\ *Corresponding Author: e14043103@gmail.com
}

\begin{abstract}
Chattering of machine tool such as lathe during cutting is traditionally an annoying and dangerous problem encountered in manufacturing process. How to control machine chatter is thus a nontrivial task for years. In this article, the dynamics of turning cutting is modelled and simulated for exploring the feasibility to suppress chattering using spindle speed variation technique. In parallel, a conventional manual lathe equipped with a self-designed sensor module serves as the experiment carrier for evaluating the performance. The results indicated that the predictive simulation is in good agreement with the experimental data essentially while ensuring feasibility. Both lumped global cutting constants (LGCC) and dual-mechanism global cutting constants (DGCC) models are adopted in analytical prediction and numerical simulation. In addition, process damping has also been added to numerical simulation, results of which are compared with cutting experiments. The critical stable depth of cut of DGCC model with process damping is shown to agree with experimental results. Sinusoidal spindle speed variation is further used to suppress turning chatter. On the same time, numerical simulation is used to find out the possible parameters which could be applied in cutting experiments. Currently, optimization of spindle speed variation is underway for further improvement on chattering control.
\end{abstract}

Keywords: turning cutting, chatter control, spindle speed variation, dynamic simulation.

\section{Introduction}

Turning process has been developed for many years. It has played a vital role in the field of manufacturing ${ }^{(1)}$ and has been widely used in various industries, particularly in producing axial-shaped workpiece. For the reasons above, lathes have also been treated as the mother of machine tools. In these times, people have continued to improve the processing efficiency without defecting the quality of products. Inevitably, machine chatter would occur and must be suppressed when people want to pursue the ultimate state of turning cutting and longer durability of the machine.

Chatter might not only cause damage to machine and tool, but also poor surface roughness and dimensional control of products. The insufficient accuracy would result in difficulties for subsequent processing and assembly. Therefore, chatter should be suppressed or controlled to avoid the previous situations. It could be analyzed and predicted with cutting system model that built from measurements.

Dynamic model of cutting system is composed of structural parameters and specific cutting coefficients. Structural parameters come from the stiffness and inertia of machine tools and tool holders. The data could be obtained from impact vibration testing ${ }^{(2)}$,which usually described as mass-spring-damper system. Specific cutting coefficients ${ }^{(3-4)}$ are settled on the geometry of tool tip, cutting parameters, and workpiece materials, which would be acquired from cutting experiments with particular cutting parameters as control variables, for example, shear coefficient $K_{t s}$, ratio of radial shear coefficient $k_{r s}$, steady ploughing coefficient $K_{t e}$, ratio of radial steady ploughing coefficient $k_{r e}$ are from the cutting experiment of changing feed rate (chip thickness).

With the settled cutting system model, chatter could be predicted. In the meanwhile, stability lobe diagram could be drawn from those cutting parameters which cause chatter for further chatter prediction. In other words, chatter should not only be anticipated and averted passively but also be 
actively controlled. There are a few methods that could suppress chatter. Most of them focus on changing the phase lag between regeneration waviness. For example, special design for tool geometry and continuous spindle speed variation. The former is limited to particular cutting condition due to fixed profiles, and the latter could be used in many cases by only changing the spindle speed depend on different cutting situations. On the other hand, spindle speed variation (SSV) is also a feasible approach. In comparison with other approaches, SSV has already shown certain advantages on flexibility. According to the cutting conditions and system structural parameters, the appropriate parameters of spindle speed variation which could break regenerative effect are able to be obtained. Therefore, the method of variable spindle speed is more flexible and this approach would be employed here for suppressing chatter induced in turning process in this paper.

\section{Model}

\subsection{Dynamic turning modal}

Here, turning force models are normally constructed with analytical and numerical integration methodology. Lamped global cutting constant (LGCC) $)^{(5)}$ does not consider dynamic force because there is only shearing force in this model. Dual-mechanism Global Cutting Constant (DGCC) separates ploughing from shearing force and contains more comprehensive mechanism (see Fig. 1). The ploughing force is divided to static and dynamic, and the dynamic one could be regarded as process damping ${ }^{(6-7)}$ in this research. The general form of force could be expressed as eq. (1). Both of them consider the specific cutting coefficient as constant and name specific cutting constant.

$\left\{\begin{array}{c}F_{t} \\ F_{f}\end{array}\right\}=K_{t s}\left\{\begin{array}{c}1 \\ k_{r s}\end{array}\right\}\left(\delta_{n}+\delta_{d}\right) b+K_{t e}\left\{\begin{array}{c}1 \\ k_{r e}\end{array}\right\} b+K_{t p}\left\{\begin{array}{c}1 \\ k_{r p}\end{array}\right\} \kappa b$

If DGCC does not contain dynamic ploughing force, this model and LGCC could be used in analytical method. Numerical method includes terms such as process damping, friction, and several modes at the same time. However, it takes more time to compute. Moreover, process damping affects more in low spindle speed. The reachable spindle speed is far lower than $\mathrm{CNC}$ lathe for it is conventional manual lathe. Hence, process damping should be considered in dynamic cutting model to improve the prediction accuracy. Yet, such condition restricts us to apply analytical method.

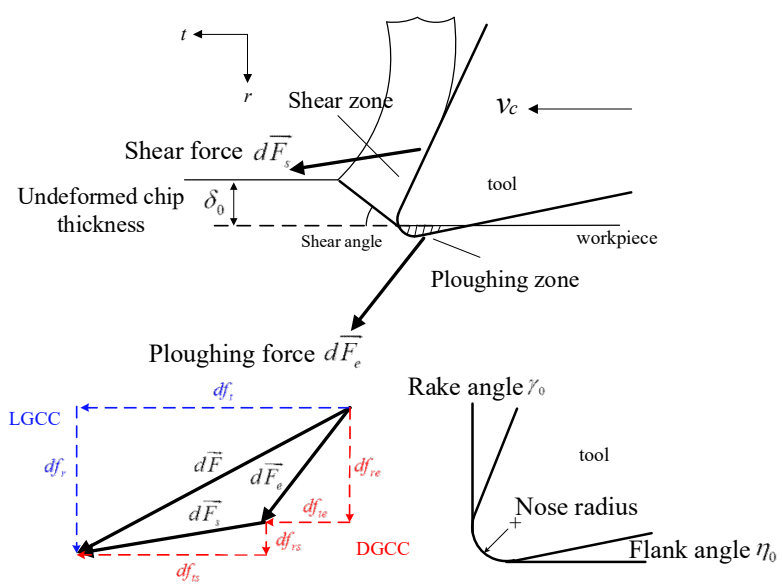

Fig. 1. Diagram of stable cutting force

\subsection{Regenerative chatter in turning process}

Regenerative chatter results from self-excitation mechanism between tool and workpiece, which would lead to change feed per revolution. Moreover, it might make the close loop of cutting dynamic stiffness and structural deflection unstable (see Fig. 2) and trigger acute vibration between workpiece and tool that causes products poor surface. This kind of vibration would not only decrease manufacturing efficiency directly but also generate negative effect on surface roughness, precision, and tool life.

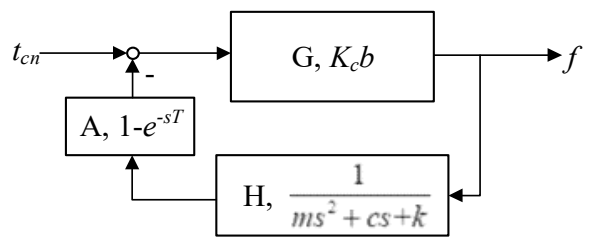

Fig. 2. Block diagram of regenerative effect

In Fig. 3. when the phase lag is small, regenerative chatter might not be apparent. However, if the phase lag is almost $180^{\circ}$, chip thickness variation would cause cutting force to change which leads to larger vibration between work piece and tool that end up in a vicious circle. Finally, regenerative chatter would be enlarged and produce enormous vibration.
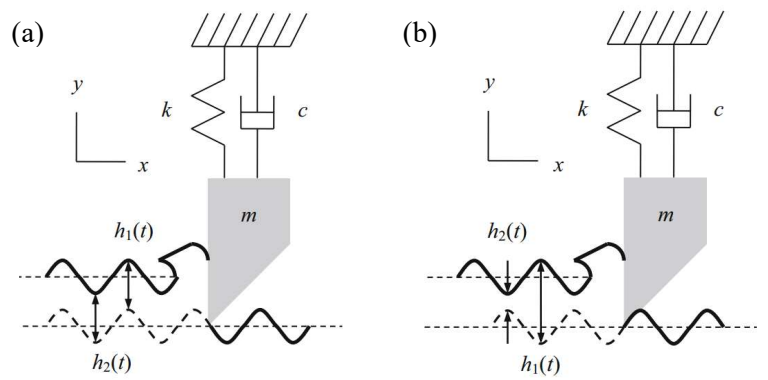

Fig. 3. Chip thickness variation of regeneration waviness (a) vaguely and (b)obviously ${ }^{(3)}$ 
From the discussions above, the effect of regenerative chatter could be described in stability lobe diagram (SLD). In SLD, the curve divides cutting parameters into stable (above the curve) and unstable (under the curve) region. Cutting parameters should be chosen from the stable region of SLD to avoid chatter during cutting.

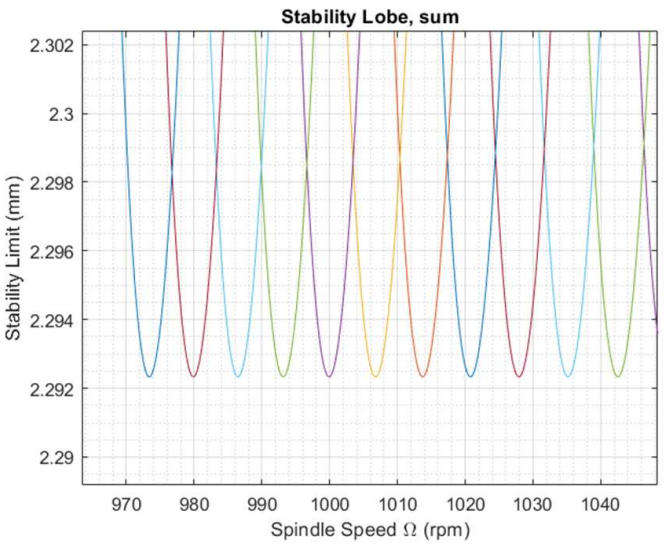

Fig. 4 Stability lobe diagram

\subsection{Chatter Control with Variable Spindle Speed}

Variable spindle speed can be realized in various kinds of waveforms such as triangle wave, square wave and sinusoidal wave. Lin, et al. ${ }^{(8)}$ proved that sinusoidal wave is the best choice. E. Al-Regib, et al. ${ }^{(9)}$ used the conception that the structural damping would consume the chatter energy. They later obtained the equation of variation spindle frequency and amplitude which could set system in the most stable conditions. They also verified the equation with experiments.

In this paper, sinusoidal spindle speed variation $\left(\mathrm{S}^{3} \mathrm{~V}\right)$ (see Fig. 5) and the equation from E. Al-Regib, et al. are used in chatter control. The best amplitude ratio $\alpha$ could be found from eq. (2) with numerical integration. Plus, the best signal frequency $f_{s}$ is based on $\alpha$ and could be obtained from eq. (3). $\alpha$ is acquired ahead, and then substituted into eq. (3) to calculate $f_{s}$.

$$
\begin{aligned}
& \frac{\Delta U_{F}}{K_{c} b Z^{2}}=-(2 \pi)^{2} f_{s} \\
& \quad \int_{0}^{2 \pi m \omega} \cos \left(\omega t-\frac{2 \pi N_{m}+\phi_{m}}{\left[1+\alpha \sin \left(2 \pi f_{s} t\right)\right]}\right) \sin (\omega t) d t \\
& f_{s}=\frac{h \Omega_{m}}{120 \pi} \sin ^{-1}\left(\frac{60 \omega_{c}}{\alpha \Omega_{m} h\left(\pi+2 \pi N_{m}\right)}-\frac{1}{\alpha}\right)
\end{aligned}
$$

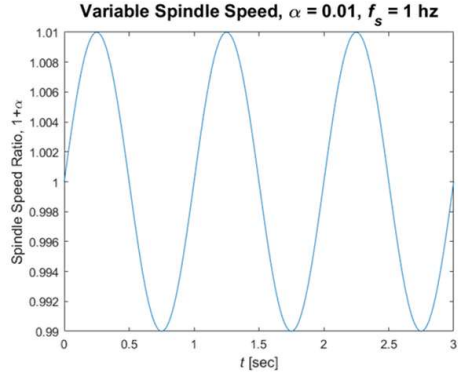

Fig. 5 sinusoidal spindle speed variation

\section{Stability lobe diagram by analytical solution and numerical simulation}

In the previous section, the analytical and numerical method have been introduced to draw the stability lobe diagram. Analytical method has higher calculation efficiency; however, numerical method takes more time but involves details. There are a few ways of numerical method. For example, "Full-discretization method, FDM", "Semi-discretization method, SDM" and "time-domain simulation". In this research, time-domain simulation is used to perform numerical method.

Besides, in order to check if the program of numerical method is valid, the results of the two methods would be compared together. Here are the two directions of force involved. Yet, we only discuss the reaction of feed direction, which means that only $H_{z y}$ and $H_{z z}$ (Table 1 ) are considered in the model. The definition of direction is in Fig. 6, and the process parameters are listed in Table 2.

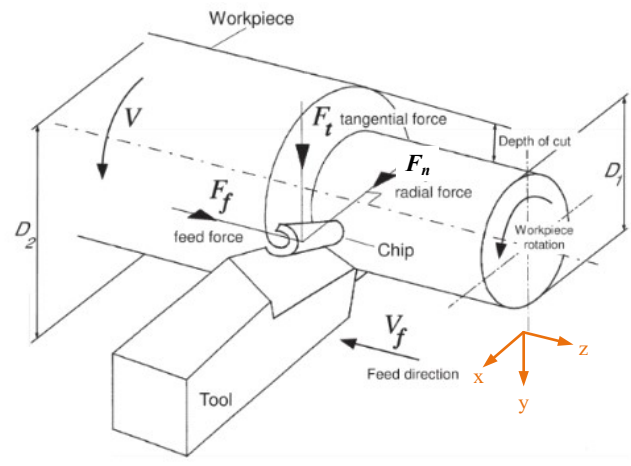

Fig. 6. Coordinate of turning system

Table 1. System structural parameters

\begin{tabular}{|l|c|c|c|c|c|}
\hline & $\begin{array}{c}\text { Natural } \\
\text { frequency } \\
f_{n}[\mathrm{~Hz}]\end{array}$ & $\begin{array}{c}\text { Damping } \\
\text { ratio } \zeta\end{array}$ & $\begin{array}{c}\text { Modal } \\
\text { stiffness } \\
k[\mathrm{~N} / \mu \mathrm{m}]\end{array}$ & $\begin{array}{c}\text { Modal } \\
\text { mass } \\
m[\mathrm{~kg}]\end{array}$ & $\begin{array}{c}\text { Modal } \\
\text { damping } \\
c[\mathrm{~N} \cdot \mathrm{s} / \mathrm{m}]\end{array}$ \\
\hline$H_{z y}$ & 2418.15 & 0.0581 & 44.7104 & 5.1632 & 341.9413 \\
\hline$H_{z z}$ & 2135.06 & 0.0345 & 59.5509 & 3.0220 & 306.3003 \\
\hline
\end{tabular}


Table 2. The process parameters

\begin{tabular}{|c|c|c|c|}
\hline & LGCC & \multicolumn{2}{|c|}{ DGCC } \\
\hline & $\begin{array}{c}\text { Shear } \\
\left(\mathrm{N} / \mathrm{mm}^{2}\right)\end{array}$ & $\begin{array}{c}\text { Shear } \\
\left(\mathrm{N} / \mathrm{mm}^{2}\right)\end{array}$ & $\begin{array}{c}\text { Static ploughing } \\
(\mathrm{N} / \mathrm{mm})\end{array}$ \\
\hline Tangential & $K_{t}=3026.8$ & $K_{t s}=2149.8$ & $K_{t e}=114.27$ \\
\hline $\begin{array}{c}\text { Ratio of axial } \\
\text { and tangential }\end{array}$ & $k_{r}=0.3560$ & $k_{r s}=0.0617$ & $k_{r e}=1.0204$ \\
\hline
\end{tabular}

\subsection{Analytical solution and time-domain simulation with LGCC model}

The governing equation of time-domain simulation is expressed as Eq. (4), where $\delta_{n}$ is nominal chip thickness, $\delta_{d}$ is dynamic chip thickness, and $\delta_{n}+\delta_{d}$ is the total chip thickness. $b$ is depth of cutting.

$$
\begin{gathered}
\left\{\begin{array}{l}
m_{z y} \ddot{z}_{y}(t) \\
m_{z z} \ddot{z}_{z}(t)
\end{array}\right\}+\left\{\begin{array}{l}
c_{z y} \dot{z}_{y}(t) \\
c_{z z} \dot{z}_{z}(t)
\end{array}\right\}+\left\{\begin{array}{l}
k_{z y} z_{y}(t) \\
k_{z z} z_{z}(t)
\end{array}\right\} \\
=-\left\{\begin{array}{c}
F_{t} \\
F_{f}
\end{array}\right\}=K_{t s}\left\{\begin{array}{c}
1 \\
k_{r s}
\end{array}\right\}\left(\delta_{n}+\delta_{d}(t)\right) b
\end{gathered}
$$

Fig. 7 (a) is drawn based on the parameters above. It is an analytical solution with $b_{\text {lim }}$ around $1.58 \mathrm{~mm}$. In Fig. 7 (b), the black line represents analytical solution in Fig. 7 (a), which is in time-domain simulation. The red star stands for unstable result while the blue circle stands for stable ones, with $b_{\text {lim }} 1.57 \mathrm{~mm}$. The two results are almost the same, which verifies for each other.
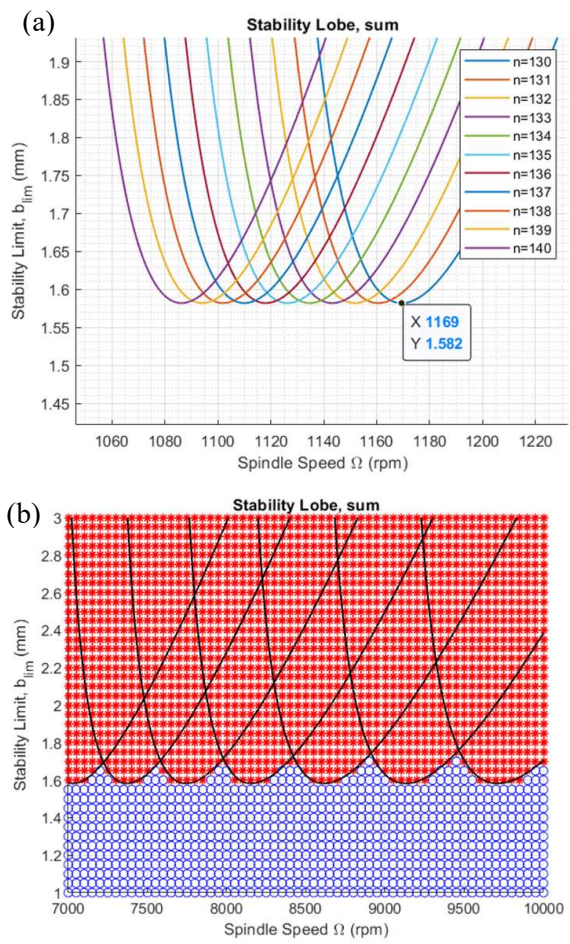

Fig. 7. Result of LGCC model (a) analytical method (b) time-domain simulation comparing with analytical method

\subsection{Analytical solution and time-domain simulation with DGCC model}

Static ploughing force is excluded for none influence in stability in analytical solution. Ploughing force is separated from shear force (DGCC), thus the system would be more stable due to the lower force acting. Eq. (5) is the governing equation of DGCC without dynamic ploughing force (process damping).

$$
\begin{aligned}
& \left\{\begin{array}{c}
m_{z y} \ddot{z}_{y}(t) \\
m_{z z} \ddot{z}_{z}(t)
\end{array}\right\}+\left\{\begin{array}{c}
c_{z y} \dot{z}_{y}(t) \\
c_{z z} \dot{z}_{z}(t)
\end{array}\right\}+\left\{\begin{array}{c}
k_{z y} z_{y}(t) \\
k_{z z} z_{z}(t)
\end{array}\right\} \\
& =-\left\{\begin{array}{c}
F_{t} \\
F_{f}
\end{array}\right\}=K_{t s}\left\{\begin{array}{c}
1 \\
k_{r s}
\end{array}\right\}\left(\delta_{n}+\delta_{d}(t)\right) b+K_{t e}\left\{\begin{array}{c}
1 \\
k_{r e}
\end{array}\right\} b
\end{aligned}
$$

Fig. 8 (a) is the analytical solution with $b_{\text {lim }}$ around $2.494 \mathrm{~mm}$. Fig. 8 (b) is the time-domain simulation with $b_{\text {lim }} 2.48 \mathrm{~mm}$. The error between the two methods is small enough to be neglected. $b_{\text {lim }}$ increases from 1.57 to $2.48 \mathrm{~mm}$, where the ratio of two kinds $b_{\text {lim }}$ nears the ratio of $K_{t s}$ and $K_{t}$, and another factor $k_{r}$ and $k_{r s}$.

(a)

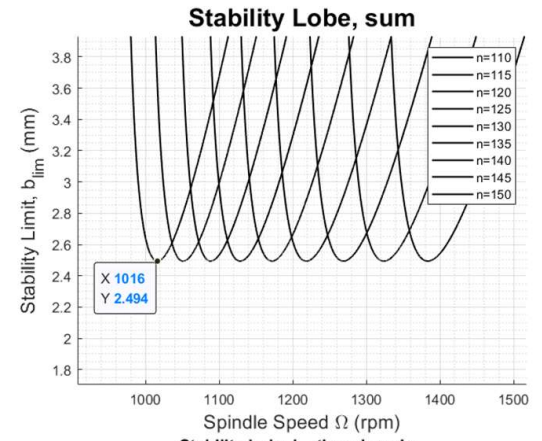

(b)

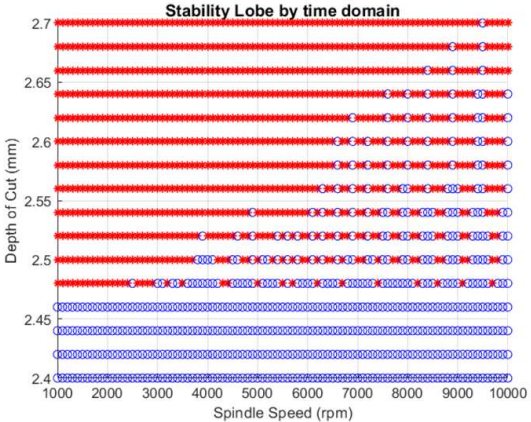

Fig. 8. The result of DGCC model without process damping

(a) analytical solution (b) time-domain simulation

Since process damping is relevant to vibration speed and cutting speed, if process damping is considered in the model, it would become dynamic cutting model. Analytical solution doesn't involve the vibration speed, so it could not be used in DGCC with process damping. Eq. (6) is the governing equation in time-domain simulation, where $K_{t p}$ and $k_{r p}$ are the parameters of process damping. 


$$
\begin{aligned}
& \left\{\begin{array}{l}
m_{z y} \ddot{z}_{y}(t) \\
m_{z z} \ddot{z}_{z}(t)
\end{array}\right\}+\left\{\begin{array}{l}
c_{z y} \dot{z}_{y}(t) \\
c_{z z} \dot{z}_{z}(t)
\end{array}\right\}+\left\{\begin{array}{l}
k_{z y} z_{y}(t) \\
k_{z z} z_{z}(t)
\end{array}\right\}=-\left\{\begin{array}{l}
F_{t} \\
F_{f}
\end{array}\right\} \\
& =K_{t s}\left\{\begin{array}{c}
1 \\
k_{r s}
\end{array}\right\}\left(\delta_{n}+\delta_{d}(t)\right) b+K_{t e}\left\{\begin{array}{c}
1 \\
k_{r e}
\end{array}\right\} b+K_{t p}\left\{\begin{array}{c}
1 \\
k_{r p}
\end{array}\right\} \kappa b
\end{aligned}
$$

Because process damping would have larger effect in lower spindle speed $(\Omega), b_{\text {lim }}$ increases as $\Omega$ decreases. Under high $\Omega, b_{\text {lim }}$ is $2.65 \mathrm{~mm}$ which is similar to DGCC model without process damping. However, when $\Omega$ reaches $1000 \mathrm{rpm}, b_{\text {lim }}$ is up to $3.15 \mathrm{~mm}$. The result verifies that process damping should be involved especially in the $\Omega$ region of conventional manual lathe.

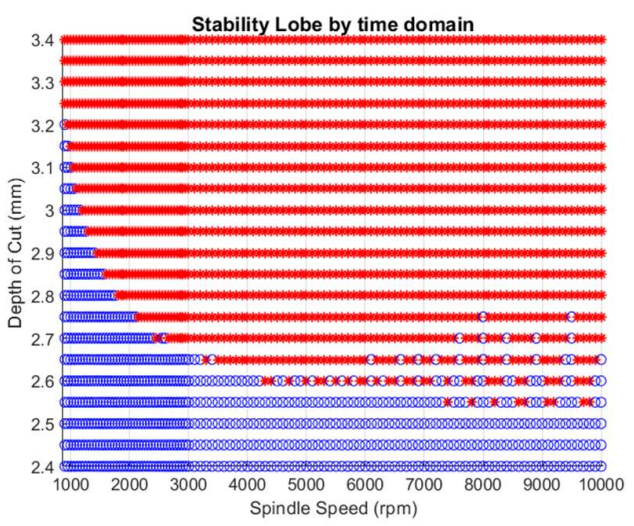

Fig. 9. Numerical method of DGCC with process damping

\subsection{Experiments}

There are several kinds of method to obtain $b_{\text {lim }}$ in the earlier sections. Since DGCC with process damping considers the most factors, it is more accurate and thus used to compare with cutting experiments. Spindle speed is a constant in this experiment, and depth of cut $b$ increases from $2.5 \mathrm{~mm}$ and adds $0.1 \mathrm{~mm}$ each time.

Table 3. lists all the cutting equipment used in this research. External axial process is performed by conventional manual lathe without any lubrication, where medium carbon steel $\mathrm{S} 45 \mathrm{C}$ is the cutting material and the insert is made of cermet. The spindle speed is set $1020 \mathrm{rpm}$, and feed rate (chip thickness) is $0.118 \mathrm{~mm} / \mathrm{rev}$.

Table 3. Model of equipment

\begin{tabular}{|c|c|}
\hline Equipment & Model \\
\hline Lathe & $\begin{array}{c}\text { HungHo ch-700C } \\
\text { Conventional manual lathe }\end{array}$ \\
\hline Tool holder & WTJNR-1616 H16 \\
\hline Insert & TNMG-160404R-2G (cermet) \\
\hline $\begin{array}{c}\text { Material of } \\
\text { experiment }\end{array}$ & $\begin{array}{c}\text { Medium carbon steel, S45C } \\
\text { Round polishing bar } \varphi 55 \mathrm{~mm}\end{array}$ \\
\hline
\end{tabular}

Fig. 10 is the acceleration of chatter turning process, where cutting parameters are in Table 4 . The acceleration of $\mathrm{y}$-direction is the largest one. Chatter frequency increases as time increases from the spectrum in y-direction at different time (Fig. 10). The overall acceleration in the period of 35.1 39 second is smaller than that in 7.1 11 second in time-domain. However, in frequency-domain, the acceleration peak is nearly doubled. It shows that vibration concentrates on a single frequency in the rear chatter cutting.

Table 4. Cutting parameters of Fig. 10 chatter experiment

\begin{tabular}{|c|c|c|}
\hline Spindle speed & Chip thickness & Depth of cut \\
\hline $1200[\mathrm{rpm}]$ & $0.118[\mathrm{~mm}]$ & $3[\mathrm{~mm}]$ \\
\hline
\end{tabular}

(a)

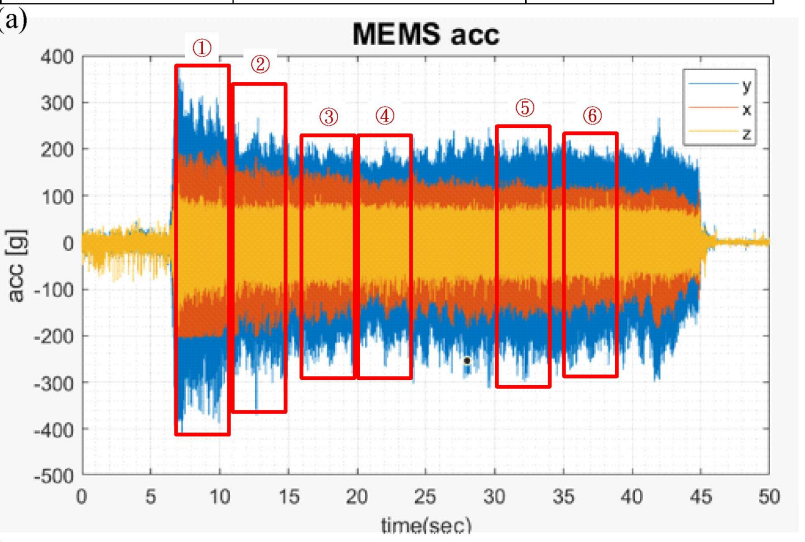

(b)
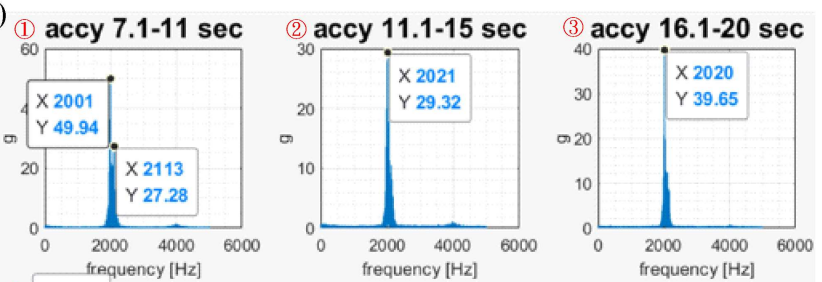

(4) $\times 203920.1-24 \mathrm{sec}$
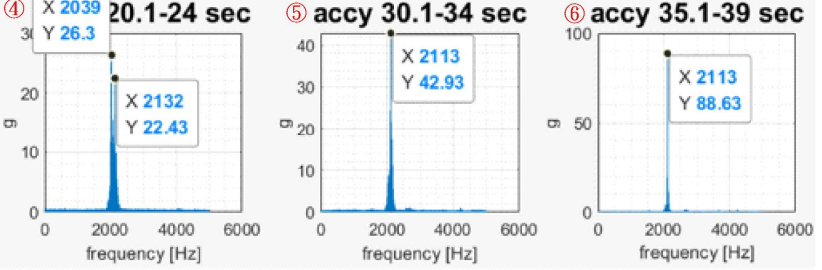

Fig. 10. Acceleration of chatter expperiment

(a) time-domain signal (b) spectrum of y-direction acceleration in different time

Fig. 11 is the result of experiments and simulation, where the black $X$ represents stable, and pink triangle stands for critical stable. In critical stable region, sometimes it would chatter. The depth of cut could not increase anymore due to the safety concern otherwise the operator would be in great danger (it is a conventional manual lathe, so there must be a person control the lathe without extra cover). 


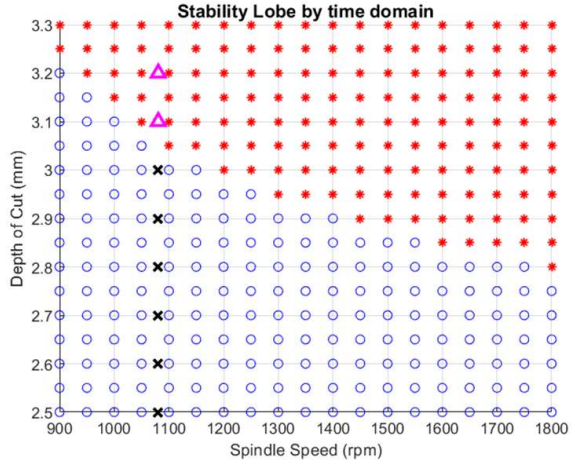

Fig. 11. Comparison of depth of cut between experiments and simulation (DGCC with process damping)

\subsection{Discussion}

From Fig. 11, the approximate $b_{\text {lim }}$ of experiments is $3.15 \mathrm{~mm}$ (the middle of critical $b$ ). We can observe results in Table 5 that DGCC with process damping performs the most similar results to experiments. On the contrary, LGCC has the largest error due to larger cutting constant. Analytical solution and time-domain simulation have almost same results with LGCC and DGCC, which could be verified that there should be no fatal mistakes in the numerical simulation. The error might come from numerical calculation.

According to the experiments, the error from vibration in experiments is usually way larger than that in numerical and analytical method. Besides, because the stability of conventional manual lathe used in this research is not so well, there might exist some unpredictable experimental errors. But the overall trends match up.

Table 5. Result of different method

\begin{tabular}{|c|c|c|}
\hline Method & Model & $b_{\text {lim }}[\mathrm{mm}]$ \\
\hline \multirow{2}{*}{$\begin{array}{c}\text { Analytical } \\
\text { solution }\end{array}$} & LGCC & 1.58 \\
\cline { 2 - 3 } & DGCC & 2.494 \\
\hline \multirow{2}{*}{$\begin{array}{c}\text { Numerical } \\
\text { simulation } \\
\text { (time-domain) }\end{array}$} & LGCC & 1.57 \\
\cline { 2 - 3 } & DGCC & 2.48 \\
\hline $\begin{array}{c}\text { Cutting } \\
\text { process damping }\end{array}$ & $2.7(3.3,1020 \mathrm{rpm})$ \\
\hline
\end{tabular}

\section{Control chatter with variable spindle speed}

Chatter influences machine tool and product quality seriously and therefore it should be suppressed or be controlled. Sinusoidal spindle speed variation $\left(\mathrm{S}^{3} \mathrm{~V}\right)^{(9)}$ is used in this research to reduce the chatter. In this paper, numerical simulation and cutting experiments are taken to verify the correctness of this model. There are two parameters to control $\mathrm{S}^{3} \mathrm{~V}$, which are amplitude ratio $\alpha$ and variation spindle speed $f_{s}$ (see Fig. 12).

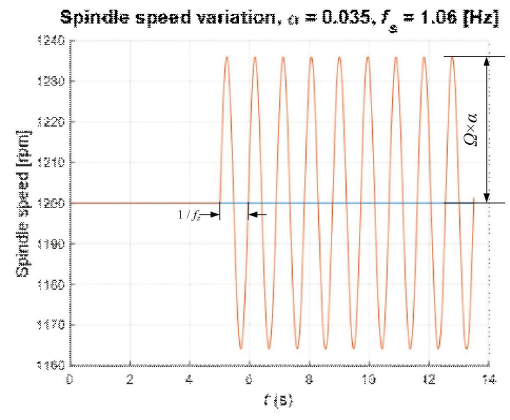

Fig. 12. Diagram of spindle speed variation

\subsection{Numerical simulation}

Spindle speed is set as a sinusoidal wave like Fig. 12. Based on Eq. (2), (3), a set of parameters could be obtained and programmed to simulate. In simulation, the parameters from reference could not suppress chatter well. So $\alpha$ would increase and then the corresponding $f_{s}$ should be found until chatter is controlled.

Fig. 13 is the displacement of simulation, where we could observe that the vibration decreases as $\alpha$ increasing. The initial parameters could not suppress chatter well. Possible reasons might include large number of lobe which leads to susceptible $\alpha$. In the low spindle speed region, stability lobe diagram becomes crowded, which causes a group of cutting parameters (spindle speed and depth of cut) belong to several lobes at same time in unstable region. According to Eq. (2), $\alpha$ is influenced by the number of lobes. The number of lobe might change and could not stay in the best parameters when executing $\mathrm{S}^{3} \mathrm{~V}$. On account of above reasons, $\alpha$ needs to be large enough to make chatter controllable.

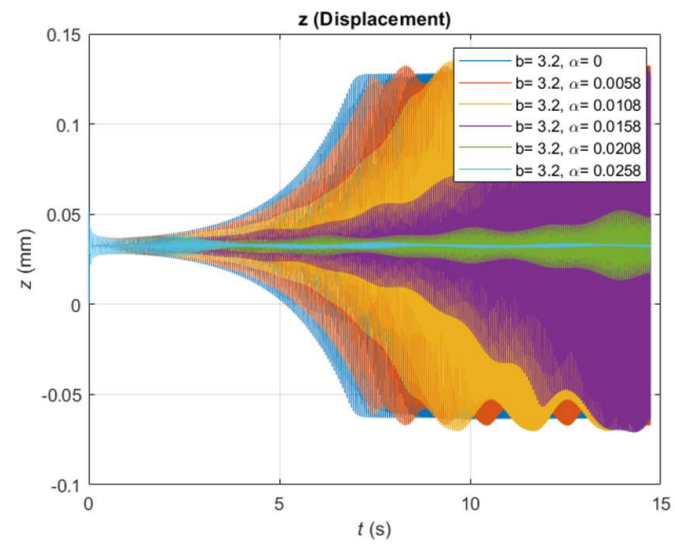

Fig. 13. Results of numerical simulation with $\mathrm{S}^{3} \mathrm{~V}$ 


\subsection{Experiments}

From previous simulation, the rough $\mathrm{S}^{3} \mathrm{~V}$ parameters could be acquired and used in cutting experiments.

Fig. 14 is the acceleration of $\mathrm{S}^{3} \mathrm{~V}$ cutting experiment, which cutting parameters are in Table 6. Spindle speed is controlled by frequency converter Delta MS300 with signal given from NI-6212 and the laptop.

The acceleration in three axes decreases almost throughout the cutting process, but there is still an obvious gap at around $22 \mathrm{sec}$. The maximum amplitude in spectrum of y-direction at $33.1 \sim 37 \mathrm{sec}$ is way smaller than that at $16.1 \sim 20 \mathrm{sec}$. The gap occurring between $6 \sim 8.5 \mathrm{sec}$ is due to hitting from the chip to the sensor, but it would not influence the whole turning process.

Table 6. Cutting parameters of Fig. $14 \mathrm{~S}^{3} \mathrm{~V}$ experiment

\begin{tabular}{|c|c|c|}
\hline Spindle speed & Chip thickness & Depth of cut \\
\hline $1150[\mathrm{rpm}]$ & $0.087[\mathrm{~mm}]$ & $3[\mathrm{~mm}]$ \\
\hline$\alpha$ & $f_{s}$ & Chatter frequency \\
\hline 0.024 & $0.4394[\mathrm{~Hz}]$ & $2103[\mathrm{~Hz}]$ \\
\hline
\end{tabular}

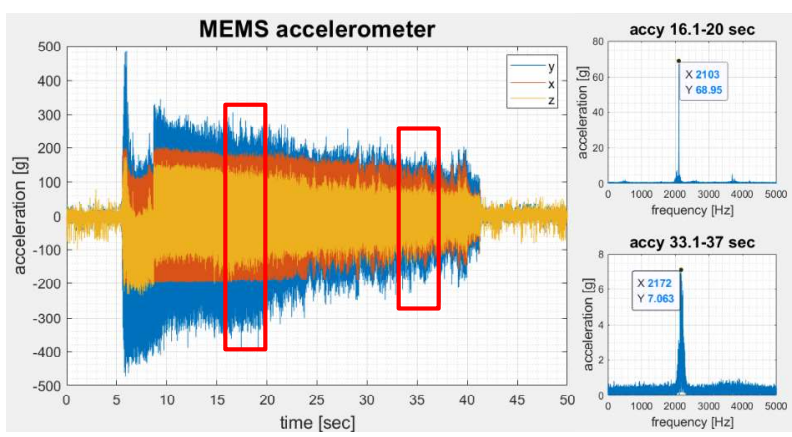

Fig. 14. Acceleration of $\mathrm{S}^{3} \mathrm{~V}$ experiment

\subsection{Discussion}

With the time-domain simulation, the initial parameters from Eq. (2) could not suppress chatter well especially in low spindle speed region. But feasible parameters could be obtained from simulation based on the results from Eq. (2), and used in cutting experiments.

Although the chatter seems to decrease by itself without $\mathrm{S}^{3} \mathrm{~V}$, the recalled data of chatter experiments in Section 3.3 shows that overall acceleration decreases. Yet, the amplitude of chatter frequency increases instead. It means that both time-domain and frequency-domain data should be involved. In addition, in the spectrum, the main vibration frequency is reduced evidently which indicates that $\mathrm{S}^{3} \mathrm{~V}$ is useful to reduce chatter.

\section{Conclusion}

Turning processes play a crucial role in cutting manufacturing industry, and it would have great influence on the product quality. In this research, a turning system model is built and its stability lobe diagram has been acquired. With different force models and methods, several SLD contrast with each other. In this paper, time-domain simulation is chosen as the numerical method.

The results of LGCC and DGCC without process damping from numerical method correspond to analytical solution. Depth of cut of LGCC is around $1.57 \mathrm{~mm}$ and for DGCC is about $2.48 \mathrm{~mm}$. The ploughing force is separated from shear force while the static ploughing force would not change the stability of system. The force applied on stability should decrease, and the results should lead to the increase of stability and the depth of cut.

Only the numerical method could be used due to nonlinear force if process damping is involved in the model. Later, it becomes a dynamic model of cutting system. Since process damping would affect obviously in low spindle speed region which is also the range of the conventional manual lath, the model should contain process damping to increase its accuracy. From time-domain simulation, depth of cut could be observed in the increasing trend as spindle speed decreasing.

Chatter cutting experiments are also performed to verify the model. There is a noticeable frequency which is so-called chatter frequency, and it tallies with simulation. Compared with cutting experiments, DGCC with process damping demonstrates the closest results to that of experiments, which verifies the correctness for each other. Depth of cut of experiments is around $3.15 \mathrm{~mm}$.

In order to operate chatter control, sinusoidal spindle speed variation is used in turning processing while referring to the results of E. Al-Regib, et al. ${ }^{(9)}$. However, the initial parameters from reference could not suppress chatter in both numerical simulation and cutting experiments. Thus, in time-domain simulation, the amplitude ratio $\alpha$ is increasing based on reference and then signal frequency $f_{s}$ would be calculated. With the conclusions above, there would be appropriate parameters from simulation that could be used in cutting experiments. The acceleration from $\mathrm{S}^{3} \mathrm{~V}$ experiments are shown in previous sections which we also changed into spectrum to analyze. In the near future, the parameters of $\mathrm{S}^{3} \mathrm{~V}$ is going to be calculated with another numerical method so called SDM, and try using different cutting parameters to extend its application. 


\section{Acknowledgment}

This paper is supported by the ministry of science and technology (MOST) of Taiwan under the contract No. 109-2221-E-006-096, 109-2622-8-006-005, 109-2622-E006-031 and 109-2221-E006-001-MY2.

\section{References}

(1) Madireddy, J. Importance of Lathe Machine in Engineering Field and its usage. Global Journal of Researches in Engineering: A Mechanical and Mechanics Engineering, 2014, 14 (6).

(2) Rao, S. S. Mechanical Vibrations, 5th Edition; Pearson, 2011.

(3) Schmitz, T. L.; Smith, K. S. Machining Dynamics; Springer, 2019.

(4) Altintas, Y. Manufacturing Automation; Cambridge Unveristy Press, 2011.

(5) Junz Wang, J. J.; Zheng, C. M. An analytical force model with shearing and ploughing mechanisms for end milling. International Journal of Machine Tools and Manufacture 2002, 42 (7), 761.

(6) Huang, C.; Wang, J. J. Mechanistic modeling of process damping in peripheral milling. 2007.

(7) Wang, J.; Uhlmann, E.; Oberschmidt, D.; Sung, C.; Perfilov, I. Critical depth of cut and asymptotic spindle speed for chatter in micro milling with process damping. CIRP Annals 2016, 65 (1), 113.

(8) Lin, S. C.; DeVor, R. E.; Kapoor, S. G. The Effects of Variable Speed Cutting on Vibration Control in Face Milling. Journal of Engineering for Industry 1990, 112 (1), 1.

(9) Al-Regib, E.; Ni, J.; Lee, S.-H. Programming spindle speed variation for machine tool chatter suppression. International Journal of Machine Tools and Manufacture 2003, 43 (12), 1229. 